\title{
"Enobrecimento Litorâneo" e os limites da aplicabilidade do Princípio da Função Socioambiental da propriedade urbana
}

\author{
"Coastal Gentrification" and the limits of the applicability of the \\ Principle of the Urban property Social and environmental \\ function
}

Simone de Araujo Pereira ${ }^{1}$

\begin{abstract}
RESUMO:
A presente reflexão decorre do questionamento acerca do limite de aplicabilidade do "Princípio da Função Socioambiental da Propriedade Privada" ao processo de "Urbanização do Litoral". Para tanto, considerando o que se reconhece como o processo de "Enobrecimento Litorâneo", o qual altera a paisagem natural para ajuste às demandas turísticas e econômicas, questiona-se em que medida é possível aplicar o "princípio da função socioambiental da propriedade", enquanto direito coletivo, às demandas individuais e, também, coletivas por equipamentos urbanos que confortam as práticas culturais do uso da praia na contemporaneidade. A pesquisa tem como objeto empírico, a ação civil pública que se desenvolveu em torno dos Bares Pé de Areia localizados na praia de Aruana, na cidade de Aracaju, no Nordeste brasileiro. A pesquisa se propôs, a partir de um recorte transversal, a elaborar um plano de análise descritivo e interpretativo no âmbito do método indutivista. A pesquisa revelou uma certa limitação na aplicação do princípio da função socioambietal da propriedade na medida em que se evidenciou a necessidade de alteração no aspecto cultural que permeia a sociedade brasileira, que é o uso social da praia a partir de equipamentos urbanos instalados ao longo da faixa-de-areia, resultando numa defesa coletiva ao direito individual dos proprietários de bares da região.
\end{abstract}

\section{PALAVRAS-CHAVE:}

Enobrecimento. Orla. Princípio. Propriedade. Socioambiental.

\begin{abstract}
:
The present reflection arises from the question about the limit of applicability of the "Principle of Socioenvironmental Function of Private Property" to the process of "Coastal Gentrification". Therefore, considering what is recognized as the process of "coastal ennobling", which alters the natural landscape to adjust to tourism and economic demands, it is questioned to what extent it is possible to apply the "principle of socio-environmental function of property" as collective right, to the individual demands and, also, collective by urban equipment that comfort the cultural practices of the use of the beach in the contemporaneity. The research has as an empirical object the public civil action that developed around the Pé de Areia Bars located in

\footnotetext{
${ }^{1}$ Pesquisadora-bolsista do Programa de apoio a pós-doutorado no Estado de Sergipe (PPDOC/SE), vinculado ao Programa de Pós-Graduação em Sociologia da Universidade Federal de Sergipe (PPGS/UFS). Membropesquisadora do Laboratório de Estudos Urbanos e Culturais (Labeurc). Doutora em Sociologia, Mestre em Antropologia, Licenciada e Bacharel em Ciência Sociais. Email: simonearaujjo@ gmail.com.
} 
the beach of Aruana, in the city of Aracaju, in the Brazilian Northeast. The research proposed, from a cross-sectional view, to elaborate a descriptive and interpretive analysis plan within the scope of the inductivist method. The research revealed a certain limitation in the application of the principle of the socioambietal function of the property to the extent that it was evidenced the necessity of alteration in the cultural aspect that permeates the Brazilian society, that is the social use of the beach from the urban equipment installed along the band-of-areaia, resulting in a collective defense of the individual rights of bar owners in the region.

\section{KEYWORDS:}

Gentrification. Border. Principle. Property. Socio-environmental.

\section{INTRODUÇÃO}

O presente trabalho desenvolve-se a partir da análise da limitação do "princípio da função socioambiental da propriedade" quando aplicado no âmbito do processo de urbanização litorânea. Nesse sentido, no domínio do processo denominado de "Enobrecimento Litorâneo"2, análogo às políticas de gentrification ${ }^{3}$, que altera a paisagem natural para ajuste às demandas turísticas e econômicas, questiona-se em que medida é possível aplicar o princípio da função social da propriedade, enquanto direito coletivo, às demandas individuais e, também, coletivas por equipamentos urbanos que confortam as práticas culturais do uso da praia na contemporaneidade.

Para tanto, o desenvolvimento está dividido em três partes. A primeira parte apresenta uma narrativa histórica acerca do conceito de "Propriedade", buscando evidenciar as concepções pelas quais a ideia de propriedade passou ao longo de sua aplicabilidade. Obviamente que é um breve relato que nos serve como fundamento para pensar a atualidade do

\footnotetext{
2 "associa-se as características típicas do enobrecimento à apropriação singular da natureza através de um duplo movimento: por um lado solapa a paisagem e suprime elementos da natureza e, por outro, evidencia como mote publicitário" (ARAUJO, 2018, P. 279).

3 O termo gentrification, cuja tradução no Brasil resultou na palavra "enobrecimento", é discutido por autores que, na década de 90, analisaram as formas de alteração da paisagem urbana que transformavam áreas degradadas em centralidades da cidade e passavam a receber investimentos públicos e privados. Dentre os autores estrangeiros que estudam a temática, pode-se citar David Harvey (1992), Mike Featherstone (1995), Niel Smith (1996) e Sharon Zukin (1995;2000); no Brasil, destaca-se o trabalho de Rogerio Proença Leite (2007).
} 
conceito e como o mesmo foi sendo alterado mediante às demandas sociais que surgiam, e, ainda, contribuindo para pensar a demanda contemporânea de adequação entre o direito civil e o direito ambiental, correlação que será tratada na parte seguinte.

Na segunda parte, evidencia-se o processo de limitação do caráter absoluto do conceito originário de propriedade a partir das questões socioambientais suscitadas. Para tanto, busca-se historicizar, através de uma análise das Constituição Brasileiras, como o direito à propriedade e suas limitações pela função social e ambiental foram sendo estabelecidas, na medida em que se analisa as possíveis controversas contidas no próprio ordenamento jurídico. Apresenta-se a análise da Constituição Imperial à Constituição Cidadã, demostrando como cada diploma tratou a matéria em questão. Verificou-se que há demandas distintas do Estado e dos cidadãos que se tornam conflitante, as quais estão relacionadas à necessidade de preservação do meio ambiente por um lado, e, do outro, as demandas culturais pelo uso da praia. Nesse sentido, evidencia-se o ambiente natural em detrimento do desenvolvimento do que se reconhece na atualidade como meio ambiente urbano-natural, o que exige modificações na concepção de vida dos indivíduos, as quais devem primar por processos de urbanização ecologicamente equilibrados e que agrida o mínimo possível o ambiente natural.

E, por fim, na terceira parte, evidencia-se o objeto empírico ao qual se busca analisar, que é a Orla Marítima, no âmbito dos princípios da Propriedade, Função Social da Propriedade e Função Socioambiental da Propriedade. A partir da definição do que a lei delimitou como Orla Marítima, busca-se pensar o limite da aplicabilidade do "princípio da função socioambiental da propriedade" ao processo de urbanização da Orla. Para a contribuir com a reflexão, toma-se como dado empírico a Ação Civil Pública que se desenvolveu em torno dos Bares Pé de Areia da "Praia de Aruana", localizada na cidade de Aracaju, na capital sergipana.

A pesquisa se propôs, a partir de um recorte transversal, a elaborar um plano de análise descritivo e interpretativo no âmbito do método indutivista' organizado tecnicamente em dois eixos fundamentais: 1) análise histórico-documental da ideia expressa no conceito de propriedade privada contido nas constituições brasileiras;2) e, levantamento do Estado da Arte sobre o tema em análise, buscando identificar entendimentos sobre a flexibilização da noção de propriedade privada. 
Finalizando o trabalho, as considerações finais apontam ao entendimento da necessidade de melhor adequação na operacionalização do "princípio da função socioambiental da propriedade" no que concerne a regulação do uso do litoral. Considerando a demanda recente e a convergência do Poder Público, seja através do Ministério Público (MP), que busca o cumprimento da lei socioambiental, ou mesmo da Advocacia Geral da União (AGU), que objetiva defender o patrimônio da união, verifica-se, no caso concreto analisado, uma limitação na aplicabilidade do "princípio da função socioambiental da propriedade" diante da demanda coletiva pelo uso da faixa-de-areia da forma como culturalmente tem sido utilizada. Exigindo muito mais do que a aplicabilidade da lei, mas uma alteração na forma de pensar dos agentes públicos e dos cidadãos, o que possibilitaria uma efetiva e plena proteção do ambiente natural mediante a urbanização demandada, e em conformidade com um uso ecologicamente equilibrado do bem natural tutelado.

\section{DESENVOLVIMENTO}

\subsection{Concepção histórica de Propriedade}

A compreensão do presente problema exige o entendimento de conceitos-chave que possibilitam pensar os limites da aplicabilidade do Princípio da Função Socioambiental da Propriedade na atualidade. Dentre os principais conceitos, verifica-se a própria ideia de "propriedade", seguindo da inserção da ideia de sua função social, de função "socioambiental", e, por fim, a ideia de Orla Marítima, que orientará o entendimento do problema proposto. Nesse sentido, inicia-se pela compreensão da ideia de "propriedade".

Vale ressaltar que antes de ser um fenômeno jurídico, a ideia de propriedade é um fenômeno social. É uma percepção que se encontra na base da constituição da própria ideia de sociedade, a qual se organiza e se orienta a partir de um determinado espaço, constituindo àquilo que futuramente viria a ser chamado de cidade, agregando-se a essa estrutura social, a própria noção de urbano. Tal espaço é determinado pela delimitação de um grupo que o toma como próprio para a sua sobrevivência, entendimento que é perceptível quando da leitura de autores 
clássicos aos estudos da formação das cidades. Um desses autores é o historiador Lewis Mumford, a partir do qual é possível falar em uma relação intrínseca do indivíduo com a terra. Embora o autor seja relutante em aceitar a mesma concepção moderna de propriedade, assegura que há uma relação direta entre o homem e a cidade. Para ele:

A propriedade, no sentido civilizado da palavra, não existia nas comunidades privadas: quando muito, as pessoas pertenciam à sua terra, mais do que a terra pertencia a elas; e dividiam seus produtos, na fartura ou na penúria. Coube a civilização criar penúrias artificiais, que mantivessem o trabalhador acorrentado à sua tarefa, para que os excedentes pudessem garantir a fartura do homem rico. (MUMFORD, 2004. p.123)

O trabalho desenvolvido por Mumford (2004) busca explicar o processo de sedentarização do homem. Que, ao longo de sua trajetória histórica, deixa de buscar alimentos já disponíveis na natureza e passa a cultivá-los, fixando-se. A partir desse processo de sedentarização é possível, para alguns autores, já se falar em propriedade: “O conceito de propriedade desenvolve-se quase que conjuntamente com a transição da fase do homem selvagem para a do homem sedentário, quando a civilização se assenta sobre determinados espaços físicos, retirando da terra seu sustento e valores”. (ASSIS, 2008, p. 782)

A partir desse fenômeno social, que torna a propriedade em si o próprio fenômeno social, a propriedade passa a ser compreendida também como um fenômeno jurídico. Desde os impérios grego e romano, verifica-se uma determinação do direito de propriedade como algo necessário a constituição da sociedade. Sendo esta uma concepção absoluta do direito à propriedade que adentra o período medieval, assim entendida por fragmentos de autores que se detiveram aos estudos do direito (ASSIS, 2008):

Embora o Direito Romano não ofereça um conceito explícito da propriedade, os juristas da Idade Média foram colher em fragmento do Digesto o princípio essencial do aspecto dominante da senhoria a se exprimir na faculdade de usar, fruir e dispor da coisa como um direito subjetivo que se opõe a terceiros, obrigados a respeitá-los (jus utendi, fruendi e disponendi) (p. 786)

As transformações ocorridas na Europa a partir do século XVIII serão decisivas para a nova configuração de mundo que estava por vir. Entre os aspectos mais marcantes dessa transformação, está a centralidade que o homem adquire no âmbito da condução da vida. Por consequência dessa centralidade, duas grandes revoluções marcam este momento: Revolução Francesa; e a Revolução industrial. Ambas possibilitam uma nova configuração social que apresenta a República como forma de governo e o Capitalismo como modelo econômico, os 
quais se tornaram hegemônico na sociedade contemporânea. Nesse sentido, tais mudanças evidenciam a figura da propriedade privada como marco da nova forma de organização social e, é a partir disso, que as concepções de propriedade vão se alterando e se adequando.

Inicialmente pautada pela teoria filosófica iluminista, emergia-se uma concepção absoluta dos direitos desses novos homens, os quais saiam da tutela de Deus para guiar, eles próprios, seus caminhos. Surge, assim, correntes distintas que passam a orientar a percepção da vida na modernidade:

O Iluminismo, pautado em suas duas correntes fundamentais, o racionalismo e o empirismo, levou à criação de duas importantes vertentes para a positivação do direito de propriedade. De um lado a vertente do contratualismo, cuja doutrina básica previa não ser o Estado fruto do acaso, mas resultado da ação racional do homem. A visão de Locke, Hobbes e Rousseau, dentre outros, de que o homem era detentor de direitos e que os levavam para a vida em sociedade foi decisiva para a cristalização dessa vertente na História da Humanidade. De outro lado, havia a vertente jusnaturalista, que buscou justamente positivar os direitos fundamentais e individuais que seriam anteriores à sociedade e ao Estado, cabendo a este respeitá-los. (ASSIS, 2008, p. 783)

Inquestionável, tais direitos eram exercidos sem limites formais, considerando a subjetividade individual na realização de seus direitos. Isso fica evidente quando analisamos especificamente uma dessas correntes, a contratualista, e em reverência a um autor em especial, o Jean-Jacques Rousseau, ao afirmar que:

o poder soberano, todo absoluto, todo sagrado, todo inviolável que é, não passa nem pode passar além dos limites das convenções gerais, e que todo homem pode dispor plenamente da parte de seus bens e da liberdade que lhe foi deixada por essas convenções (ROUSSEAU, 2002[1762], p. 42)

Em outro trecho, o autor iluminista esclarece a diferença entre liberdade natural, a qual é perdida em favor dos direitos civis, os quais se tornam absolutos na medida em que dispõe, ao seu título, de suas vontades enquanto possuidor. Senão, vejamos:

Reduzamos todo este balanço a termos fáceis de comparar. O que o homem perde pelo contrato social é a liberdade natural e um direito ilimitado a tudo que o tenta e pode alcançar; o que ganha é a liberdade civil e a propriedade de tudo o que possui. Para que não haja engano em suas compensações, é necessário distinguir a liberdade natural, limitada pelas forças do indivíduo, da liberdade civil que é limitada pela liberdade geral, e a posse, que não é senão o efeito da força ou do direito do primeiro ocupante, da propriedade, que só pode ser baseada num título positivo (ROUSSEAU, 2002[1762], p. 12).

É a partir dos autores contratualistas, tal qual como Rousseau, John Locke e Thomas Hobbes, que o direito de propriedade adquire uma melhor definição. A positivação dessas 
percepções pode ser encontrada em documentos legais que atestam a necessidade da propriedade:

\begin{abstract}
Essa positivação ocorre com o surgimento da Carta Constitucional norteamericana, oriunda da Convenção de Filadélfia, de 1787, e na Declaração dos Direitos do Homem e do Cidadão, de 1789, na França. A partir dessas Cartas constitucionais, a incolumidade do direito de propriedade passa por gerações, sendo considerado um direito absoluto, imprescritível, inalienável. (ASSIS, 2008, p. 784, grifo nosso)
\end{abstract}

Embora as constituições contemporâneas não tenham se furtado em garantir do direito de propriedade, a evidência do direito de propriedade passa a ser questionado no âmbito das correntes filosóficas definidas como Romântica e Crítica, que surgem no leste europeu. Diante das demandas surgidas no âmbito das sociedades que passavam a se configurar como republicanas e economicamente capitalistas, as teorias da época começam a questionar o caráter absoluto do direito de propriedade. O que gera novas percepções acerca do direito de propriedade e de sua adequação aos novos direitos também constitucionais que surgiam.

Dentre as variadas mudanças que ocorreram, uma que contribuiu para pensar o problema colocado, decorre da alteração que exige que o direito de propriedade passe, também, a ser compreendido como uma obrigação. Segundo Assim (2008):

\footnotetext{
Não seria exagero anotarmos que tanto a Constituição mexicana, de 1917, quanto a Constituição de Weimar, de 1919, dão um novo tratamento para o conceito de direito de propriedade, tratamento esse que faz com que aquela deixe de ser vista apenas como um direito, passando a ser concebida também como uma obrigação, no sentido de que a propriedade obriga seu detentor a mantê-la. (p. 785)
}

Nesse sentido, a obrigação de mantê-la, apresenta-se, entre tantas outros obrigação para se continuar como detentor, a questão socioambiental. Verifica-se a necessidade de limitação da liberdade civil apresentada pelos iluministas em relação ao uso das propriedades privadas. Segundo Orlando Gomes: "o direito complexo, absoluto, perpétuo e exclusivo, pelo qual uma coisa fica submetida à vontade de uma pessoa, [mas] com as limitações da lei” (GOMES, 2007, p. 103). Dentre tais limitações do uso da propriedade, encontra-se, em um debate mais contemporâneo, a limitação no âmbito das questões ambientais, cuja natureza se apresenta como limitadora da ação humana enquanto agente transformador da própria natureza. Nesse sentido, a ideia de princípio socioambiental da propriedade emerge como garantidor dos limites da ação humana, o qual será discutido nas próximas linhas, e como forma garantidora da manutenção do direito de propriedade. 


\subsection{O Princípio Socioambiental da Propriedade}

A partir das transformações do século XVIII, intensificadas nos séculos seguintes, o modelo de propriedade seguiu absorvendo limitações, principalmente em decorrência do entendimento de que as demandas coletivas devem se sobrepor aos direitos individuais. No caso específico da Orla Marítima no Brasil, verifica-se evidente discussão acerca do direito de uso das terras litorâneas. De um lado se constata uma demanda coletiva por Bares Pé de Areia, por outro lado, encontra-se uma demanda individual pela propriedade das estruturas arquitetônicas dispostas ao longo da faixa-de-areia, e ainda, a demanda da União pela proteção da área, legalmente definida como de uso público. Essa discussão aponta à necessidade de resolução estatal, porém, o Estado se torna parte uma vez que tais áreas são consideradas pela constituição como um patrimônio da união e um "bem" de todos. Obviamente que essa propriedade Estatal recebe contorno próprio, na medida em que é de sua competência zelar pelo uso coletivo da área. No entanto, esse uso coletivo gera uma demanda cultural do uso da faixa-de-areia que resulta na construção de estruturas que se tornam propriedades privadas. O que se questiona neste item, corresponde ao limite de ação do Estado na Zona Costeira diante das tensas relações entre o público e o privado que se coloca na discussão. Ou seja, de um lado o coletivo e o individual demandando o uso de áreas que são consideradas de interesse público na perspectiva ambiental. Emerge-se assim, uma divergência entre direitos individuais e interesses coletivos, que engloba três princípios fundamentais, o de propriedade, da função social da propriedade e da função socioambiental da propriedade.

Porém, antes de adentrar à ideia e limites apresentados pelo Princípio da Função Social da Propriedade, é preciso ressaltar que as limitações ao direito de propriedade se dão, inicialmente, pelo que se entende por "Princípio da Função Social da Propriedade". Tal princípio, segundo Augusto Geraldo Teizen Júnior (2004), apresenta-se por duas características fundamentais: 1) a de que "o proprietário tem o dever e, portanto, o poder de empregar a coisa que possui na satisfação das necessidades individuais e, especialmente, das suas próprias de empregar a coisa no desenvolvimento de sua atividade física, intelectual e moral"; e, 2) aquela que "o proprietário tem o dever e, portanto, o poder de empregar a sua coisa na satisfação das 
necessidades comuns de uma coletividade nacional inteira ou de coletividades secundárias" (TEIZEN JÚNIOR, 2004. P. 154).

O problema segundo o próprio Teizen (2004), é a própria dinâmica que a noção de propriedade está submetida:

[...] é sob seu aspecto dinâmico que a propriedade já foi e continuará a ser alvo de disputa ideológica, visto que, neste campo jurídico-econômico, a chamada função social da propriedade tem seus contornos, não mais de bens móveis e imóveis, porém transmudada, funcionalizada em universitas júris (conjunto de direitos) e universitas facti (conjunto de objetos). Essa funcionalização da propriedade, albergada no Ordenamento Constitucional, em seu aspecto dinâmico, nos conduz a outros aspectos dessa funcionalização. Como uma unidade produtiva as propriedades em geral, em especial as grandes corporações, são tidas como um bem de produção a serviço da sociedade. (TEIZEN JÚNIOR, 2004, p. 12)

Dessa forma, pensar a propriedade não corresponde apenas ao direito individual no âmbito da coletividade, que o é, mas que também é preciso considerar o aspecto ideológico que se impõe na produção da dinamicidade e da forma como o direito de propriedade se delimita. A ideia clara de que a função social se estabelece na "não ociosidade", resguarda uma série de posturas de agentes públicos no desenvolvimento de leis que buscam regular o direito à propriedade. Embora não seja o objetivo apresentar uma reflexão sobre os fundamentos ideológicos que sustentam os limites do uso da propriedade no Brasil, far-se-á, uma apresentação das mudanças do conceito nas Constituições Brasileiras para compreendermos como foi sendo delimitado o direito à propriedade no Brasil.

A “Constituição Política do Império do Brazil”, de 25 de março de 1824, coloca a propriedade como base dos Direitos Civis, Políticos e dos Cidadãos Brasileiros, garantindolhes a inviolabilidade. Assim, expresso no:

Art. 179. A inviolabilidade dos Direitos Civis, e Politicos dos Cidadãos Brazileiros, que tem por base a liberdade, a segurança individual, e a propriedade, é garantida pela Constituição do Imperio, pela maneira seguinte. (BRASIL, 1824)

A ideia de propriedade contida no caput está descrita no inciso XXII do mesmo artigo:

XXII. É garantido o Direito de Propriedade em toda a sua plenitude. Se o bem publico legalmente verificado exigir o uso, e emprego da Propriedade do Cidadão, será elle préviamente indemnisado do valor della. A Lei marcará os casos, em que terá logar esta unica excepção, e dará as regras para se determinar a indemnização (BRASIL, 1824). 
É explicito o caráter pleno da propriedade, correlato ao que verificamos no item anterior acerca da ideia absoluta deste direito. Porém, a segunda parte do artigo 179, delimita o uso da propriedade em decorrência de uma demanda do "bem público" e indica que lei específica regulamentará tal indicativo constitucional.

Em setembro de 1826, foi apresentada a lei que regulamentava o então artigo 179 da constituição, a qual dispõe dos casos possíveis de "desapropriação da propriedade particular". As exceções às desapropriações, segundo a referida lei, estão descritas nos artigos $1^{\circ}$ e $2^{\circ}$ :

Art. $1^{\circ}$ A unica excepção feita á plenitude do direito de propriedade conforme a Constituição do Imperio, Tit. $8 .^{\circ}$ art. $179, \S 22$, terá logar quando o bem publico exigir uso, ou emprego da propriedade do cidadão por necessidade nos casos seguintes:

1. Defesa do Estado.

2. Segurança Publica.

3. Soccorro publico em tempo de fome, ou outra extraordinaria calamidade.

4. Salubridade publica.

Art. $2^{\circ}$ Terá logar a mesma excepção, quando o bem publico exigir uso, ou emprego da propriedade do cidadão por utilidade previamente verificada por acto do Poder Legislativo, nos casos seguintes:

1. Instituições de caridade.

2. Fundações de casas de instrucção de mocidade.

3. Commodidade geral.

4. Decoração publica.

Ou seja, a partir da leitura de tais artigos, verifica-se que a desapropriação se dará em decorrência de uma demanda pública, que visa proteger o bem coletivo maior. Assim, a propriedade privada é suprimida pela demanda social, devendo, ainda, o proprietário ser indenizado. Não há hipótese na lei que possibilite a supressão do direito de propriedade sem a devida indenização, o que reforça a inviolabilidade e a plenitude da propriedade.

A primeira constituição republicana, e a segunda do Brasil, data de 1881. A “Constituição da República dos Estados Unidos do Brasil”, promulgada em 24 de fevereiro, em seu artigo 72, retira a propriedade do entendimento anterior que o reconhece como uma base dos direitos invioláveis e o coloca, ele próprio, como um desses direitos invioláveis. Senão, vejamos:

Art.72 - A Constituição assegura a brasileiros e a estrangeiros residentes no paiz a inviolabilidade dos direitos concernentes a liberdade, a segurança individual e à propriedade, nos termos seguintes: (BRASIL, 1881) 
No parágrafo 17 do mesmo artigo, encontra-se a reafirmação do caráter pleno da propriedade e estabelece a possibilidade de exceção: " $\$ 17$. O direito de propriedade mantemse em toda a sua plenitude, salvo a desapropriação por necessidade, ou utilidade pública, mediante indemnização prévia." (BRASIL, 1881). Embora se apresente como uma norma de eficácia contida, não se verificou uma lei reguladora desse artigo, relativo a forma e possibilidade de desapropriação.

Já a Constituição da República dos Estados Unidos do Brasil, publicada em 16 julho de 1934, em seu Capítulo II, que versa sobre as Garantias e Direitos Individuais, assegura no artigo 113 a inviolabilidade de propriedade: “Art 113 - A Constituição assegura a brasileiros e a estrangeiros residentes no País a inviolabilidade dos direitos concernentes à liberdade, à subsistência, à segurança individual e à propriedade, nos termos seguintes:”. Acerca dos termos seguintes, citado no exto constitucional, descrevo àquele referente ao tema de interesse da presente reflexão:

17) É garantido o direito de propriedade, que não poderá ser exercido contra o interesse social ou coletivo, na forma que a lei determinar. A desapropriação por necessidade ou utilidade pública far-se-á nos termos da lei, mediante prévia e justa indenização. Em caso de perigo iminente, como guerra ou comoção intestina, poderão as autoridades competentes usar da propriedade particular até onde o bem público o exija, ressalvado o direito à indenização ulterior. (BRASIL, 1934)

Haja vista as mudanças ocorridas na Constituição de 1934 em relação a de 1881, vale destacar dois aspectos: 1) a retirada da plenitude do direito de propriedade; e, 2) a submissão da garantia do direito de propriedade ao interesse coletivo. Desse modo, é possível verificar que a lei passa a tomar novos contornos ao condensar duas formas de limitação ao direito de propriedade. Na primeira parte do parágrafo 17 , verifica-se a subordinação do direito de propriedade aos interesses coletivos, que podem ser entendidos como aqueles demandados da coletividade; e, na segunda parte, subordina ao "bem público", relativo àqueles que correspondem a ação Estatal de proteção da coisa pública.

É, ainda na Constituição de 1934, que o direito de usucapir um bem imóvel surge, então descritos no artigo 125:

Art 125 - Todo brasileiro que, não sendo proprietário rural ou urbano, ocupar, por dez anos contínuos, sem oposição nem reconhecimento de domínio alheio, um trecho de terra até dez hectares, tornando-o produtivo por seu trabalho e tendo nele a sua morada, adquirirá o domínio do solo, mediante sentença declaratória devidamente transcrita. (BRASIL, 1934) 
A partir desse momento, a usucapião rural e urbano estavam constitucionalmente instituídos. A ocupação por mais de dez anos de bens rurais e urbanos, em consonância com a ausência de reconhecimento de domínio e de oposição ao uso, garantiria ao ocupante o domínio do solo.

Após 15 anos, o país passou a dispor de uma nova constituição. Em 18 de setembro de 1946, publica-se a "Constituição dos Estados Unidos do Brasil”, que, em relação a propriedade, não houve alteração, sendo transcrito na íntegra o artigo 72 da constituição anterior, mas desta vez no artigo 141 e no parágrafo 17, que passa a ser o 16, mantendo-se no Capítulo II, que trata dos Direitos e Garantias Individuais

Art 141 - A Constituição assegura aos brasileiros e aos estrangeiros residentes no País a inviolabilidade dos direitos concernentes à vida, à liberdade, a segurança individual e à propriedade, nos termos seguintes: (BRASIL, 1946)

Porém, no ano de 1964, houve uma emenda à Constituição que alterou, significativamente, o parágrafo 16. A transcrição de ambos nos permite melhor compreensão das alterações realizadas:

$\S 16$ - É garantido o direito de propriedade, salvo o caso de desapropriação por necessidade ou utilidade pública, ou por interesse social, mediante prévia e justa indenização em dinheiro. Em caso de perigo iminente, como guerra ou comoção intestina, as autoridades competentes poderão usar da propriedade particular, se assim o exigir o bem público, ficando, todavia, assegurado o direito a indenização ulterior. (BRASIL, 1946)

$\S$ 16. É garantido o direito de propriedade, salvo o caso de desapropriação por necessidade ou utilidade pública, ou por interêsse social, mediante prévia e justa indenização em dinheiro, com a exceção prevista no $\$ 1^{\circ}$ do art. 147. Em caso de perigo iminente, como guerra ou comoção intestina, as autoridades competentes poderão usar da propriedade particular, se assim o exigir o bem público, ficando, todavia, assegurado o direito a indenização ulterior. (Redação dada pela Emenda Constitucional n ${ }^{\circ} 10$, de 1964) (Grifo Nosso, alterações realizadas pela Emenda)

A alteração no parágrafo 16 se deu para a introdução de uma exceção ao pagamento de indenização, a qual se encontra descrita e grifada na citação anterior. O artigo 147 não constava na Constituição anterior, e foi inserido, na de 1946, no Capítulo II, mas desta vez no Título V, que versa sobre a Ordem Econômica e Social. Tal artigo, afirma que: “Art 147 - O uso da propriedade será condicionado ao bem-estar social. A lei poderá, com observância do disposto no art. 141, $\S 16$, promover a justa distribuição da propriedade, com igual oportunidade para todos" (BRASIL, 1946). Desta forma, ficava o uso da propriedade totalmente subordinado ao bem-estar social e, buscando assegurar a ideia de igualdade, promover a justa distribuição. 
A mesma Emenda Constitucional de 1964, que alterou o parágrafo 16, também inseriu seis parágrafos no artigo 147.

$\S 1^{\circ}$ Para os fins previstos neste artigo, a União poderá promover desapropriação da propriedade territorial rural, mediante pagamento da prévia e justa indenização em títulos especiais da dívida pública, com cláusula de exata correção monetária, segundo índices fixados pelo Conselho Nacional de Economia, resgatáveis no prazo máximo de vinte anos, em parcelas anuais sucessivas, assegurada a sua aceitação a qualquer tempo, como meio de pagamento de até cinqüenta por cento do Impôsto Territorial Rural e como pagamento do preço de terras públicas.

$\S 2^{\circ}$ A lei disporá, sôbre o volume anual ou periódico das emissões, bem como sôbre as características dos títulos, a taxa dos juros, o prazo e as condições de resgate.

$\S 3^{\circ}$ A desapropriação de que trata o $\S 1^{\circ}$ é da competência exclusiva da União e limitar-se-á às áreas incluídas nas zonas prioritárias, fixadas em decreto do Poder Executivo, só recaindo sôbre propriedades rurais cuja forma de exploração contrarie o disposto neste artigo, conforme fôr definido em lei.

$\S 4^{\circ} \mathrm{A}$ indenização em títulos somente se fará quando se tratar de latifúndio, como tal conceituado em lei, excetuadas as benfeitorias necessárias e úteis, que serão sempre pagas em dinheiro.

$\S 5^{\circ}$ Os planos que envolvem desapropriação para fins de reforma agrária serão aprovados por decreto do Poder Executivo, e sua execução será da competência de órgãos colegiados, constituídos por brasileiros de notável saber e idoneidade, nomeados pelo Presidente da República, depois de aprovada a indicação pelo Senado Federal.

$\S 6^{\circ}$ Nos casos de desapropriação, na forma do $\S 1^{\circ}$ do presente artigo, os proprietários ficarão isentos dos impostos federais, estaduais e municipais que incidam sôbre a transferência da propriedade desapropriada.

Tais incisos, como pôde ser verificado pela leitura, buscam regulamentar o disposto do caput e indicam à necessidade de lei específica que verse sobre o tema. Vale ressaltar que o caput do artigo 147 não abaliza quaisquer tipos de propriedade, diferentemente, os parágrafos atuam na delimitação da propriedade rural.

A Constituição da República Federativa do Brasil de 1967, promulgada em 24 de janeiro de 1967, em seu capítulo IV, dos Direitos e Garantias Individuais, repete o caráter inviolável da propriedade, mas agora disposto no:

Art 150 - A Constituição assegura aos brasileiros e aos estrangeiros residentes no Pais a inviolabilidade dos direitos concernentes à vida, à liberdade, à segurança e à propriedade, nos termos seguintes: (BRASIL, 1967)

Ao informar os termos, mais uma vez repete o texto contido no parágrafo 16 da constituição anterior, mas agora no parágrafo 22 e com a devida alteração que indica, não mais o artigo 147, mas o 157, como se verifica abaixo:

$\S 22$ - É garantido o direito de propriedade, salvo o caso de desapropriação por necessidade ou utilidade pública ou por interesse social, mediante prévia e justa 
indenização em dinheiro, ressalvado o disposto no art. $157, \S 1^{\circ}$. Em caso de perigo público iminente, as autoridades competentes poderão usar da propriedade particular, assegurada ao proprietário indenização ulterior.

Porém, a novidade trazida pelo texto Constituição decorre da inserção da norma que versa sobre a "função social da propriedade", introduzindo-o como um princípio à ordem econômica e social. Senão, vejamos o que diz o inciso III do artigo 157, que está contido no Título III, que versa sobre a Ordem Social e Econômica: “Art 157 - A ordem econômica tem por fim realizar a justiça social, com base nos seguintes princípios: III - função social da propriedade" (BRASIL, 1967). Demais parágrafos, análogos aos inseridos à Constituição de 1946, pela Emenda Constitucional de número 10, expõem sobre condições de desapropriação. Posteriormente, houve uma modificação no parágrafo $1^{\circ}$, a redação inicial dispunha da possibilidade de pagamento prévio de justa indenização, que perde a obrigação de ser prévia através do "Ato Institucional no 9 de 1969".

A Constituição da República Federativa do Brasil de 1988, já no Título II, quando versa sobre os Direitos e Garantias Fundamentais, no capítulo sobre os Direito Individuais e Coletivos, expressa, em seu artigo $5^{\circ}$, que: “Art. $5^{\circ}$ Todos são iguais perante a lei, sem distinção de qualquer natureza, garantindo-se aos brasileiros e aos estrangeiros residentes no País a inviolabilidade do direito à vida, à liberdade, à igualdade, à segurança e à propriedade, nos termos seguintes:" (BRASIL, 1988). O direito à propriedade, expresso no caput, recebe, através dos incisos, delimitações:

XXII - é garantido o direito de propriedade;

XXIII - a propriedade atenderá a sua função social;

XXV - no caso de iminente perigo público, a autoridade competente poderá usar de propriedade particular, assegurada ao proprietário indenização ulterior, se houver dano;

XXVI - a pequena propriedade rural, assim definida em lei, desde que trabalhada pela família, não será objeto de penhora para pagamento de débitos decorrentes de sua atividade produtiva, dispondo a lei sobre os meios de financiar o seu desenvolvimento; (BRASIL, 1988)

Repetindo a Constituição anterior, a de 1988 também apresenta a função social da propriedade como princípio, mas desta vez no Capítulo I, que aborda os Princípios Gerais da Atividade Econômica, que está contido no Título VII, o qual normatiza a Ordem Econômica e Financeira, não mais social, como na norma anterior. O artigo 170, expressa que "A ordem econômica, fundada na valorização do trabalho humano e na livre iniciativa, tem por fim assegurar a todos existência digna, conforme os ditames da justiça social, observados os 
seguintes princípios". Os incisos que interessam à reflexão são o II e o III, que são apresentados como princípios da ordem econômica, estado tal ordem subordinada aos "ditames da justiça social", a "propriedade privada" e "função social da propriedade".

A Constituição ainda apresenta o entendimento acerca do cumprimento da função social da propriedade urbana e rural. No Capítulo II, do mesmo título, que trata da política urbana, o artigo 182 expõe que a política urbana tem como objetivo ordenar o pleno desenvolvimento das funções sociais da cidade e garantir o bem-estar de seus habitantes. E, esclarece em seu parágrafo $2^{\circ}$ que: " $\$ 2^{\circ}$ A propriedade urbana cumpre sua função social quando atende às exigências fundamentais de ordenação da cidade expressas no plano diretor." (BRASIL, 1998). Ainda no mesmo título, mas no Capítulo III, que versa sobre a Política Agrícola e Fundiária e da Reforma Agrária, o artigo 186 dispõe que “A função social é cumprida quando a propriedade rural atende, simultaneamente, segundo critérios e graus de exigência estabelecidos em lei, aos seguintes requisitos:”. Os requisitos dispostos são:

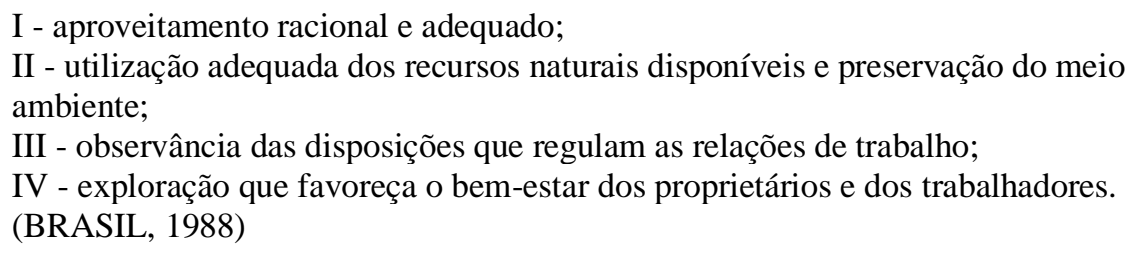

E, ainda apresenta os casos em que a propriedade ganha um caráter absoluto, quando expõe no artigo 185 as situações que são insuscetíveis de desapropriação para fins de reforma agrária.

I - a pequena e média propriedade rural, assim definida em lei, desde que seu proprietário não possua outra;

II - a propriedade produtiva.

Parágrafo único. A lei garantirá tratamento especial à propriedade produtiva e fixará normas para o cumprimento dos requisitos relativos a sua função social. (BRASIL, 1988)

Pela primeira vez, o texto constitucional fala da aquisição da propriedade de outrem pela posse, constando no artigo 191 as condições, sendo ressalvado apenas os imóveis públicos:

Art. 191. Aquele que, não sendo proprietário de imóvel rural ou urbano, possua como seu, por cinco anos ininterruptos, sem oposição, área de terra, em zona rural, não superior a cinquienta hectares, tornando-a produtiva por seu trabalho ou de sua família, tendo nela sua moradia, adquirir-lhe-á a propriedade. (BRASIL, 1988) 
A Emenda Constitucional 81, de 2014, estabelece novas formas de limitações à propriedade privada, cuja desapropriação de propriedades urbanas e rurais não está condicionada ao pagamento de indenizações:

\begin{abstract}
Art. 243. As propriedades rurais e urbanas de qualquer região do País onde forem localizadas culturas ilegais de plantas psicotrópicas ou a exploração de trabalho escravo na forma da lei serão expropriadas e destinadas à reforma agrária e a programas de habitação popular, sem qualquer indenização ao proprietário e sem prejuízo de outras sanções previstas em lei, observado, no que couber, o disposto no art. 5\%. (Redação dada pela Emenda Constitucional no 81, de 2014)
\end{abstract}

A Constituição de 88 também inova ao apresentar um caso específico de reconhecimento de propriedade, disposto nos Atos das Disposições Constitucionais Transitórios, "Art. 68. Aos remanescentes das comunidades dos quilombos que estejam ocupando suas terras é reconhecida a propriedade definitiva, devendo o Estado emitir-lhes os títulos respectivos.” (BRASIL, 1988)

Juntamente com o princípio da função social da propriedade, a constituição também garante o direito de propriedade. Controversos, o direito à propriedade não se subordina à função social. O texto constitucional não expressa nenhuma forma de interpretação nesse sentido, porém, verifica-se que há uma sobreposição do princípio da função social da propriedade ao princípio da propriedade.

Em que pese, discuta-se, atualmente, acerca do conceito abstrato de propriedade, que se efetiva no uso (DANTAS, 2015), ou seja, com a posse, colocando o debate no patamar da defesa direta pela função social da posse e não da propriedade, não recai sobre a presente reflexão, tal contenda. Mas sim, a própria noção de propriedade e função socioambiental da propriedade, que no caso em discussão não perpassa pelo debate acerca da propriedade abstrata e a posse, mas pela propriedade individual e o direito coletivo ao meu ambiente ecologicamente equilibrado.

Apresentar a forma como o princípio da propriedade passa a ser tratada pela constituição, permite-nos perceber como a propriedade vai sendo limitada pelo social, ou seja, pela demanda do outro pela posse em detrimento da propriedade de outrem. E, recentemente, como veremos, às limitações impostas por questões ambientais, colocando-nos no cerne da discussão, em que não mais se perde apenas a propriedade, como também a posse, e não mais se transfere, mas se destrói, em virtude da natureza. 
Diferentemente do princípio da função social da propriedade, o princípio da função socioambiental da propriedade não é um princípio constitucional. Embora, dentre os fundamentos, para resolver demandas sobre determina propriedade que esteja de alguma forma comprometendo o equilíbrio natural, encontra-se o artigo 225 da Constituição Federal e o artigo 1.229 do Código Civil.

O direito à propriedade passa a ser confrontado com o caput do artigo 255: "Todos têm direito ao meio ambiente ecologicamente equilibrado, bem de uso comum do povo e essencial à sadia qualidade de vida, impondo-se ao Poder Público e à coletividade o dever de defendê-lo e preservá-lo para as presentes e futuras gerações" (BRASIL, 1998). A emergência do direito ambiental e as exigências que o colocam à frente dos demais direitos decorrem da evidente supressão dos recursos ambientais e da previsão da escassez de tais recursos.

Bem como, pelo disposto no parágrafo primeiro do artigo 1.229 do Código Civil:

$\S 1$ o $\mathrm{O}$ direito de propriedade deve ser exercido em consonância com as suas finalidades econômicas e sociais e de modo que sejam preservados, de conformidade com o estabelecido em lei especial, a flora, a fauna, as belezas naturais, o equilíbrio ecológico e o patrimônio histórico e artístico, bem como evitada a poluição do ar e das águas."

Entretanto, o Princípio da Função Socioambiental da Propriedade está expresso apenas na Lei Federa $n^{\circ} 11.428$, de dezembro de 2006, a qual dispõe "sobre a utilização e proteção da vegetação nativa do Bioma Mata Atlântica, e dá outras providências" (BRASIL, 2006). Especificamente no artigo $6^{\circ}$ do Capítulo II, que versa sobre os Objetivos e Princípio do Regime Jurídico do Bioma Mata Atlântica. Segundo este artigo:

\footnotetext{
Art. 6o A proteção e a utilização do Bioma Mata Atlântica têm por objetivo geral o desenvolvimento sustentável e, por objetivos específicos, a salvaguarda da biodiversidade, da saúde humana, dos valores paisagísticos, estéticos e turísticos, do regime hídrico e da estabilidade social.

Parágrafo único. Na proteção e na utilização do Bioma Mata Atlântica, serão observados os princípios da função socioambiental da propriedade, da eqüidade intergeracional, da prevenção, da precaução, do usuário-pagador, da transparência das informações e atos, da gestão democrática, da celeridade procedimental, da gratuidade dos serviços administrativos prestados ao pequeno produtor rural e às populações tradicionais e do respeito ao direito de propriedade. (BRASIL, 2006)
}

A partir do exposto, verifica-se que há uma utilização análoga acerca do Princípio da Função Socioambiental da Propriedade às demais demandas, que estão além do Bioma Mata Atlântica. Tem-se estendido às demandas do Estado por recuperar suas terras, àquelas 
delimitadas como Patrimônio da União, que no estudo em tela, corresponde, não à posse pelo estado dos bens dispostos em áreas litorâneas, mas a retirada da coisa em litígio para a plena proteção ambiental, como verificaremos no item posterior.

Contudo, no âmbito da discussão colocada por Teizen Júnior (2004), o que se verifica ao longo das últimas constituições, principalmente a de 1964 e de 1988, intensificada por leis regulamentadoras de artigos Constitucionais de eficácia limitada, é a efetivação de ações análogas cunhadas em princípios e fundamentos político-ideológicos de "transferência de renda", em que grupos socioeconômicos com aportes financeiros mais adequado às necessidades básicas são convidados compulsoriamente, no âmbito de um princípio de "pacto social", em prol de uma "justiça social", a contribuir com o "bem-estar" (FACHIN, 1988) mínimo de uma parcela da população que compõe um grupo social que não dispõe de condições econômicas adequadas. E, ainda, no âmbito dos interesses ambientais, a retomada da posse pela União das terras classificadas como Patrimônio da União e, em determinados casos, a derrubada de imóveis com uso e posse regular.

\section{3 “Orla Marítima”: Da propriedade e posse à destruição (ou construção).}

O processo de desenvolvimento urbano é cada vez mais intenso. Diante desse processo, verifica-se a expansão das cidades para seus extremos. Nas cidades litorâneas "defrontante para o mar"4, o oceano se apesenta como um limite a esta expansão. Nesse sentido, a urbanização fronteiriça, entre o continente e o mar, compreende variadas questões sociais, especificamente no âmbito da adequação legal que a envolve. Diferentemente de outros ambientes da cidade, a "Orla" se configura pela urbanização pungente e pelo ambiente natural que a caracteriza. Sendo esta uma área turística, que é recorrentemente evidenciada como atrativo principal de determinadas cidades brasileiras, o processo de urbanização é cada vez mais evidente.

Essa breve introdução já nos anuncia os problemas socio-jurídicos que se apresentam no âmbito da "Orla". Primeiramente, verifica-se que estamos falando de um ambiente natural,

\footnotetext{
${ }^{4}$ Segundo o IBGE, são as cidades que fazem limite direto com o mar.
} 
logo, recai sobre esta região a legislação ambiental pertinente. Segundo, constata-se que corresponde a uma área reconhecida como Patrimônio da União. E, por fim, que, socialmente, resguarda dois problemas, o primeiro em relação ao processo histórico de povoamento da região, sendo constituído o direito individual de propriedade ou de posse de bens imóveis; e, o segundo, relacionado ao seu caráter turístico, que se apresenta por uma demanda coletiva pela região. Tais circunstâncias colocam em discussão três princípios fundamentais ao direito e uso da propriedade privada, sendo eles: 1) O princípio da propriedade (BRASIL, 1988); 2) O princípio da função social da propriedade (BRASIL, 1988); e, 3) O princípio da função socioambiental da propriedade (BRASIL, 2006). Os quais já foram apresentados anteriormente, mas que agora passa a ser correlacionados ao problema efetivamente posto.

Nesse sentido, considerando o processo de "Enobrecimento Litorâneo" 5 , que altera a paisagem natural para ajuste às demandas turísticas e econômicas, questiona-se em que medida é possível verificar a aplicação dos princípios elencados anteriormente no âmbito de questões que envolve interesse Público, o direito Privado e a obrigação Estatal. O interesse público advém do caráter cultural do uso da praia no brasil, o qual requer equipamentos urbanos que confortam as práticas usuais da praia na contemporaneidade. O interesse privado resulta das casas de moradia, de veraneio e de empreendimentos comerciais, este em sua maioria, que privatizam a Orla Marítima. E, o Estatal, que tem a Orla como patrimônio e precisa regular ao uso comum de todos.

Para seguir ao desenvolvimento da questão colocada, faz-se necessário delimitar a área específica em suas fronteiras jurídicas que se aborda na presente reflexão. É preciso compreender o que é a Orla Marítima. E, posteriormente, analiso os limites dos princípios já relacionados no âmbito da aplicabilidade ao ordenamento da Orla Marítima.

A noção de Orla é uma conceituação recente e, de forma recorrente, é tomado como sinônimo de praia e litoral. Desta forma, faz-se necessária a apresentação de conceitos que orientaram o desenvolvimento da pesquisa, esclarecendo o que especificamente se entende por "Orla", distinguindo-o de zona costeira, litoral e praia.

\footnotetext{
5 “associa-se as características típicas do enobrecimento à apropriação singular da natureza através de um duplo movimento: por um lado solapa a paisagem e suprime elementos da natureza e, por outro, evidencia como mote publicitário" (ARAUJO, 2018, P. 279).
} 
"Zona Costeira", "Litoral” e "Orla" são, em geral, tomadas como definições correlatas, mas, para fins desta reflexão, é preciso atentar às distinções por ora apresentadas. $\mathrm{O}$ "Projeto Orla", instituído pelo governo federal, busca apresentar definições operacionais à preservação e regulação do desenvolvimento litorâneo, verifica que a bibliografia internacional e programas similares apresentam o conceito de Zona Costeira a partir de diferentes definições:

No geral, duas concepções predominam na literatura especializada: a primeira busca captar este espaço como uma unidade natural, passível de ser delimitada no terreno por aspectos físicos ou biológicos; a segunda visão entende tratar-se de uma unidade político-administrativa, que não necessariamente se apresenta com limites naturais evidentes (2006, p. 21).

Em geral, a concepção natural predomina em estudos acadêmicos, enquanto a administrativa corresponde à projetos governamentais. No Brasil, a Zona Costeira, segundo a lei $\mathrm{n}^{\circ}$ 7.661, de 16 de maio de 1988, que Institui o Plano Nacional de Gerenciamento Costeiro, em seu parágrafo único, é definida como "o espaço geográfico de interação do ar, do mar e da terra, incluindo seus recursos renováveis ou não, abrangendo uma faixa marítima e outra terrestre, que serão definidas pelo Plano" ". Esta definição, torna-se limitada diante da variedade da costa brasileira, então, quando da elaboração do Plano Nacional de Desenvolvimento Costeiro II (PNDG II, 2004), aceita-se os limites político-administrativos dos municípios como critério. Assim, a zona costeira passa a ser delimitada por duas faixas, a marítima e a terrestre:

\footnotetext{
Na faixa marítima, considera-se todo o mar territorial como inserido na zona costeira, sendo o limite deste determinado pela Convenção das Nações Unidas sobre o Direito do Mar nas 12 milhas náuticas contadas da linha de base da costa. De acordo com esse documento, trata-se da área prioritária para a pesca artesanal.

$\mathrm{Na}$ faixa terrestre, considera-se todo o território dos municípios qualificados como costeiros segundo critérios estabelecidos no Plano. Assim, as fronteiras internas municipais fornecem a delimitação da zona costeira em terra.
}

Por outro lado, "litoral" não foi objeto da legislação, mas é possível apreender como culturalmente utilizamos tal categoria. A etimologia da palavra "litoral" contribui para pensar o subsistema antrópico. Derivada do latim litoralis $^{7}$, é composta por litus, que significa Costa, margem ou borda, e alis (-al), que, correlacionado ao radical, torna-o relativo à, pertencente à. Litoral seria a classificação daquilo que é relativo ou pertencente à Costa.

\footnotetext{
${ }^{6}$ Fonte: http://www.planalto.gov.br/ccivil_03/leis/L7661.htm

${ }^{7}$ Fonte: http://etimologias.dechile.net/?litoral
} 
Assim, pode-se compreender os limites da Zona Costeira como relativos ao litoral, caracteriza-se pelo entendimento de "lugar", no sentido que apresenta Leite (2007), o qual é definido "como demarcações físicas e simbólicas no espaço, cujos usos os qualificam e lhes atribuem sentidos de pertencimento, orientando ações sociais e sendo por estas delimitados reflexivamente" (p. 35). Neste sentido, o litoral é definido para fins desta pesquisa como o espaço delimitado na Zona Costeira pelos municípios defrontantes com o mar, que desenvolvem atividades relativas ao mar e que apresentam demarcações físicas e simbólicas no espaço, que são qualificados pelos usos que lhes atribuem sentido de pertencimento ao litoral.

E, por fim, ao que mais interessa a presente reflexão, apresenta-se a definição de Orla Marítima. A qual se distingue da noção de "Zona Costeira" e "Litoral". O "Projeto Orla" apresenta um significado de Orla satisfatório para o desenvolvimento da reflexão: "A orla marítima pode ser definida como unidade geográfica inclusa na zona costeira, delimitada pela faixa de interface entre a terra firme e do mar" (2006, p. 27). É esse um "ambiente caracterizase pelo equilíbrio morfodinâmico, no qual interagem fenômenos terrestres e marinhos, sendo os processos geológicos e oceanográficos os elementos básicos de conformação dos principais tipos de orla" (2006, p.07).

Neste sentido, a Orla é o espaço que comumente se entende como praia, seja arenosa ou de seixos, costas rochosas (altas e baixas), falésias erodíveis, planícies lamosas, pântanos, manguezais e formações recifais. As Orlas, assim como as outras categorizações, "possui uma porção aquática, uma porção em terra e uma faixa de contato e sobreposição entre estes meios (variável no tempo e no espaço, basicamente em função do mecanismo das marés" (Projeto Orla, 2006, p. 28). As porções são descritas como zona marinha - a isóbata de 10 metros, e a terrestre - 50 (cinquenta) metros em áreas urbanizadas ou 200 (duzentos) metros em áreas não urbanizadas.

Às Orlas são apresentadas duas tipologias genéricas, que tomam dois critérios como base: o primeiro que considera as características fisiográficas (geografia física) "que indicam o nível de vulnerabilidade da orla em face de processos naturais e antrópicos"; e, o segundo, que "verificação dos índices de ocupação humana instalada que referenciam os níveis de povoamento e a intensidade dos usos praticados de cada localidade" (2006, p. 31). O segundo critério é um dos aspectos relevantes à pesquisa, mas que nos anuncia, pode-se dizer, uma 
terceira tipologia, a qual convém a análise, podendo ser sinteticamente como jurídico-social, que pode vir a verificar o índice de litígios que envolvem o processo de ocupação e usos da "Orla Marítima". Negligenciado no âmbito da elaboração do Projeto Orla, pode-se propor o desenvolvimento de trabalhos que aprofundem a matéria e busquem esclarecer os limites das demandas jurídicas no espaço urbano-natural. Porém, no âmbito de um trabalho de conclusão de curso de uma graduação, apresenta-se, apenas, as controvérsias da aplicação dos princípios em questão e as suas limitações como fundamentos à resolução dos conflitos.

Dentre alguns dos conflitos existentes, pode-se ressaltar as tensões entre a noção de público e de privado; o direito coletivo em confronto com o Direito Estatal, que por ora parece assumir um caráter privado, na medida em que negligencia a demanda coletiva pelo uso da Orla; os interesses de uso da coletividade e os direitos individuais.

Embora consideremos que o conceito de propriedade é um conceito dinâmico e que se alterou, saindo de um caráter absoluto à limitação dada por novos conceitos constitucionais que foram surgindo, verifica-se que se apresentam de forma conflitante. Em que pese a utilização de preceitos ambientais constitucionais na defesa do princípio socioambiental da propriedade, é preciso não perder de vista que o mesmo corresponde a um princípio de proteção da Mata Atlântica, permitindo questionamentos acerca de sua aplicabilidade em âmbito geral.

Para que se mantenham como proprietários de seus imóveis na Orla Marítima, é preciso que se cumpra determinadas obrigações, que, no caso específico do socioambiental, é a proteção ao meio ambiente. Verificou-se, ainda, uma demanda contemporânea de adequação entre o direito civil e o direito ambiental, enquanto uma regulação que busca adequar o direito civil, em sua relação com o direito das coisas, com foco específico ao direito de propriedade, ao direito ambiental, o qual têm demandando dos Estados e cidadãos uma mudança de concepção da relação social que se tem estabelecido com o ambiente natural ao desenvolvimento do que se reconhece na atualidade como meio ambiente urbano-natural, na busca de se atingir processos de urbanização ecologicamente equilibrados.

Quando se analisa variadas situações no Brasil, em que a propriedade, e em determinados casos a posse, foi questionada, percebe-se o turn dado entre a função social da propriedade e a função socioambiental da propriedade. Se na primeira havia uma alternância entre posseiros, ou seja, entre um proprietário e alguém que, por situações adversa, passa é ser 
detentor do bem, agora verifica-se que o bem é destruído em razão do meio ambiente. Não estou levantando questionamento absoluto acerca da destruição predatória da natureza, mas apenas atentando às condições culturais postas na sociedade e dos limites do ordenamento que busca adequar as situações à melhor condução da ordem social.

Ao analisar o caso específico ocorrido na cidade de Aracaju, na praia de Aruana, verifica-se que é uma condição sine qua non para o que se observa na presente reflexão. Em 2014, a Advocacia Geral da União (AGU), passa a demandar dos órgãos responsáveis, ou supostamente responsáveis pelo gerenciamento da Orla Marítima, explicações sobre os bens imóveis construídos na faixa-de-areia da praia de Aruana. Foram acionados a Secretaria do Patrimônio da União (SPU), Administração Estadual de Meio Ambiente (ADEMA), Instituto Brasileiro de Meio Ambiente e dos Recursos Naturais (IBAMA) e Secretaria Municipal de Meio Ambiente. Não obtendo respostas consistentes, a AGU resolveu encaminhar ao Ministério Público Federal (MPF) o relato da situação, ou seja, a informação de que o patrimônio da união estava sendo utilizado e não lhe foram entregues estudos de impacto, liberações, concessões ou o que lhe valesse como forma de regulamentação das estruturas físicas existentes da faixa-deareia.

No mesmo ano, inicia-se uma ação civil pública, a qual segue com o número 080258536-2014.4.05.8500. As partes compõem-se pela União, de um lado, e do outro, os donos de bares e restaurantes e órgãos da administração pública com competência para regular e administrar a área. Os argumentos elencados pelo MPF estão descritos pela: 1) "situação de total desordem no que tange às ocupações nesse balneário" (TINOCO, 2014, p.21); 2) "total desconformidade com as exigências ambientais mínimas" (TINOCO, 2014, p.21) 3) impedimento do "livre acesso à praia"; 4) e, por fim, em decorrência do que se entende por “evidente favelização da área” (TINOCO, 2014, p. 22). O entendimento geral é o de que:

Esse quadro acarreta por um lado a completa favelização de algumas áreas e por outro
a elitização e privatização do espaço público. Em parte dele, alguns estabelecimentos
de luxo constroem verdadeiras fortalezas de concreto em faixa de areia e modificam
de forma profunda e indelével a paisagem natural, com consequências desastrosas
para o meio ambiente, tais como a completa retirada e destruição de áreas de duna e a
consequente erosão do solo. (TINOCO, 2014, p. 22).

A ação seguiu ao pedido de completa retirada dos bares e restaurantes da faixa-deareia. Após várias negociações e, a partir de conversas com os órgãos da administração pública 
responsáveis pelo gerenciamento da área e donos de bares, chegou-se ao entendimento mais razoável aos interessados, definiu-se pela manutenção dos bares e restaurantes com a devida adequação à proteção do meio ambiente.

A partir da análise da contenda que resultou na ação civil pública, foi possível o entendimento de que há a latente necessidade de melhor adequação na operacionalização do "princípio da função socioambiental da propriedade", conjuntamente ao "princípio da propriedade" e da "função social da propriedade", no que concerne a regulação do uso do litoral.

Analisando o esforço de órgãos da administração pública, bem como do poder judiciários, pelo cumprimento da legislação vigente e proteção do patrimônio comum a todos, verifica-se, no caso concreto em discussão, uma tensão não solucionada entre aplicabilidade do "princípio da função socioambiental da propriedade" na resolução de conflitos gerados entre as estruturas físicas demanda pelas práticas e simbolismos culturais que se desenvolveram entorno do uso da praia e as demandas da legislação ambiental e da necessidade de gerência do governo federal de seus bens. O que resulta, em certa medida, na necessidade de reanálise do limite da atuação do Estado na promoção do bem-estar, uma vez que pode ultrapassar os interesses individuas e coletivo.

Assim, o processo de Enobrecimento Litorâneo atua por sua lógica de alteração da paisagem natural para ajuste às demandas turísticas e econômicas e, em determinados casos, a demanda coletiva pelo uso da praia em uma experiência menos natural, em barracas, banho doce e sobra, tensionado com o Princípio Socioambiental da Propriedade e, em casos específicos, como o da Praia de Aruana, a demanda coletiva sobrepõe a legislação vigente pelos fundamentos do interesse coletivo dos usuários e dos proprietários.

\section{CONSIDERAÇÕES FINAIS}

O presente trabalho se desenvolveu a partir do questionamento acerca da possibilidade de adequação do Princípio da Função Socioambiental da Propriedade, que se confronta entre o dever Estatal de proteção do meu ambiente para a coletividade e a demanda de uso coletivo de 
um bem que se torna privado, que são as estruturas físicas dos Bares Pé de Areia. Ou seja, o Estado tem por obrigação a proteção ambiental e, ainda, resguarda a obrigação de cuidar de seus bens, que é o caso da Orla Marítima, por estar localizada na Zona Costeira, sendo este um patrimônio da União. Junto a isso, tem-se o interesse duplamente coletivo, o de proteção do meio ambienta costeiro e a demanda da coletividade pelo uso da praia através de suas estruturas físicas, tais como os Bares Pé de Areia.

Para compreensão dessas tensões entre o público e o privado, o direito da coletividade ao meio ambiente e os interesses coletivos de usos da praia diante dos direitos individuais, a reflexão partiu da análise de categorias-chave capazes de fornecer subsídios à compreensão do problema colocado. Desse modo, a partir da compreensão da categoria propriedade, pode-se verificar a dinamicidade do conceito, que seguiu do seu caráter absoluto às limitações postas por demandas específicas. E, ainda, verificou-se a ideia central que se desenvolve o princípio da função social da propriedade e o da função socioambiental da propriedade. Nesse sentido, para que se mantenha a propriedade é preciso que o proprietário cumpra determinadas obrigações, que, no caso específico do socioambiental, é a proteção ao meio ambiente.

$\mathrm{Na}$ análise do objeto em questão, o litígio envolvendo os Bares Pé de Areia da praia de Aruana em Aracaju, verificou-se que a justiça buscou adequar a demanda da União pela posse da área com um acordo entre as partes envolvidas. O que permitiu o entendimento de que se verifica a necessidade de melhor adequação na operacionalização do "princípio da função socioambiental da propriedade" no que concerne a regulação do uso do litoral. Considerando a demanda recente pela regulação do litoral, seja através do Ministério Público (MP) que busca o cumprimento da lei socioambiental ou mesmo da Advocacia Geral da União (AGU) que busca defender o patrimônio da União, verifica-se, no caso concreto analisado, um entrave na aplicabilidade do "princípio da função socioambiental da propriedade" diante da demanda coletiva pelo uso da faixa-de-areia da forma como culturalmente tem sido utilizada.

O litoral brasileiro, como vimos, foi historicamente povoado e utilizado de variadas formas. Atualmente, o uso voltado ao lazer é o mais proeminente, que resulta em processos de intervenção da paisagem que tenho chamado de "Enobrecimento Litorâneo". Nesse caso específico da praia da Aruana, a demanda coletiva acabou se sobrepondo ao direito social ao meio ambiente e, mesmo, à demanda do Estado. Prevaleceu a cultura da coletividade em 
detrimento do meio ambiente natural. O que faz considerar que se é exigindo muito mais do que a aplicabilidade da lei, mas, sim, uma alteração na forma de pensar dos agentes públicos e dos cidadãos, o que possibilitaria uma efetiva e plena concretização da proteção do ambiente natural mediante a urbanização demandada, e uma conformidade com um uso ecologicamente equilibrado do bem natural tutelado.

\section{REFERÊNCIAS}

ANTUNES, Paulo de Bessa. Direito Ambiental. 13 a ed. Rev. E atual. Rio de Janeiro: Lumen Juris, 2011.

ARAUJO, Simone. Enobrecimento Litorâneo: a Orla de Atalaia. Revista TOMO, São Cristóvão, Sergipe, Brasil, n. 32, p. 269-306, jan./jun. 2018.

ASSIS, Luiz Gustavo Bambini de. A evolução do direito de propriedade ao longo dos textos constitucionais. Revista da Faculdade de Direito da Universidade de São Paulo v. 103 p. 781 - 791 jan./dez. 2008.

BRASIL. Lei $N^{o}$ 11.428. Dispõe sobre a utilização e proteção da vegetação nativa do Bioma Mata Atlântica, e dá outras providências. Brasília, DF, dez, 2006. Disponível em: < http://www.planalto.gov.br/ccivIl_03/_Ato2004-2006/2006/Lei/L11428.htm>. Acesso em: 11 out. 2018.

Lei 11.428 de 22 de dezembro de 2006. Dispõe sobre a utilização e proteção da vegetação nativa do Bioma Mata Atlântica, e dá outras providências.

. Constituição da República Federativa do Brasil de 1988. Brasília, 05 out. 1988.

Constituição da República Federativa do Brasil de 1967. Brasília, 24 jan.1967

. Constituição dos Estados Unidos do Brasil. Brasília, 18 set. 1946.

. Constituição da República dos Estados Unidos do Brasil. Brasília, 16 jul. 1934.

Constituição da República dos Estados Unidos do Brasil. Brasília, 24 de fev. 1881.

BRAZIL. Constituição Política do Império do Brazil. Brasília, 25 mar. 1824.

BRASIL. PROJETO ORLA - Fundamentos para uma Gestão Compartilhada.Secretariado Patrimônio da União/SPU, do Ministério do Planejamento, Orçamento e Gestão/MP e Secretaria de Mudanças Climáticas e Qualidade Ambiental/SQA, do Ministério do Meio Ambiente/MMA. Brasília, 2003. 
PROJETO ORLA - Guia de Implementação. Secretaria do Patrimônio daUnião/SPU, do Ministério do Planejamento, Orçamento e Gestão/MP e Secretaria de Mudanças Climáticas e Qualidade Ambiental/SQA, doMinistério do Meio Ambiente/MMA. Brasília, 2005.

PROJETO ORLA - Implementação em Territórios com Urbanização Consolidada. Secretaria do Patrimônio da União/SPU, do Ministério doPlanejamento, Orçamento e Gestão/MP e Secretaria de Mudanças Climáticase Qualidade Ambiental/SQA, do Ministério do Meio Ambiente/MMA. Brasília, 2006.

PROJETO ORLA - Manual de Gestão. Secretaria do Patrimônio daUnião/SPU, do Ministério do Planejamento, Orçamento e Gestão/MP eSecretaria de Mudanças Climáticas e Qualidade Ambiental/SQA, doMinistério do Meio Ambiente/MMA. Brasília, 2005.

PROJETO ORLA - Subsídios para um Projeto de Gestão, Secretaria do Patrimônio da União/SPU, do Ministério do Planejamento, Orçamento e Gestão/MP e Secretaria de Mudanças Climáticas e Qualidade Ambiental/SQA, do Ministério do Meio Ambiente/MMA. Brasília, 2003.

DANTAS, Marcus Eduardo de Carvalho. Da função social da propriedade à função social da posse exercida pelo proprietário: Uma proposta de releitura do princípio constitucional. Revista de Informação Legislativa. Ano 52 Número 205 jan./mar. 2015.

FACHIN, Luiz Edison. A função social da posse e a propriedade contemporânea (uma perspectiva da usucapião imobiliária rural. Porto Alegre: Fabris, 1988. 102p.

GOMES, Orlando. Direitos Reais. 19.ed. atual. por Luiz Edson Fachin. Rio de Janeiro: Forense, 2007.

LATOUR, B. ([2009] 2014). Um Prometeu cauteloso? Alguns passos rumo a uma filosofia do design (com especial atenção a Peter Slotedijk). Agitpropn. 58. Agitpropn: revista brasileira de design.

LOBO, Paulo Luiz Neto. Constitucionalização do Direito Civil. Revista de Informação Legislativa. Brasília, n. 141, p. 99-109, jan./mar. 1999.

MACHADO, Paulo Affonso Leme. Direito Ambiental Brasileiro. 23 a ed. Rev., ampl. E atual. São Paulo: Malheiros Editores, 2015.

MUMFORD, Lewis. A cidade na história - suas origens, transformações e perspectivas. Martins Fontes/unb, 2004.

O’DONNELL, Julia. Um Rio Atlântico: Culturas urbanas e estilos de vida na invenção de Copacabana. Tese de Doutorado, Mudeu Nacional, 2011.

PEREIRA, A. Q. A urbanização vai à praia:Vilegiatura Marítima e Metrópole no Nordeste do Brasil. Fortaleza: Edições UFC. 2014 
ROUSSEAU, Jean-Jaques. Do contrato social. ROQUE DA SILVA, Rolando. Edição eletrônica: Ed. Ridendo Castigat Mores. Disponível em: < http://www.dominiopublico.gov.br/pesquisa/DetalheObraForm.do?select_action=\&co_obra=2 244>, acesso realizado em 20/09/2018.

LEITE, Rogerio P.. Contra-usos da Cidade: lugares e espaço público na experiência urbana contemporânea. Campinas: UNICAMP, 2007.

SECRETARIA DO PATRIMÔNIO DA UNIÃO, Documentos de Gestão, disponíveis no endereço http:/www.spu.planejamento.gov.br:

TEIZEN JÚNIOR, Augusto Geraldo. A função social no Código Civil. São Paulo: RT, 2004.

VELHO, G. A Utopia Urbana. Rio de Janeiro: Zahar, 1977.

Submetido em: 21/04/2019

Aceito em: 30/10/2019 